\title{
Investigation of the Spatial Variability of Steel Weight Loss and Corrosion Cracking: A Novel X-ray Technique
}

\author{
Sopokhem Lim, Haitao Jiang, and Mitsuyoshi Akiyama \\ Department of Civil and Environmental Engineering, Waseda University
}

\begin{abstract}
The performance of corrosion-affected RC members depends strongly on localized damages of reinforcement. Therefore, modeling the spatial variability of steel corrosion is very important for the assessment of the remaining service life of corroded structures or time for maintenance. To study the changes of spatial variability of steel weight loss over time, a continuous monitoring is necessary. In this paper, a novel procedure of X-ray technique application in monitoring the spatial growth of a corroded bar in a RC specimen is demonstrated along with the digital image processing of X-ray images to estimate the steel weight loss. The relationship of steel weight loss and corrosion cracking is studied at different stages of corrosion. The validity of the estimation method of steel weight loss is also presented.
\end{abstract}

\section{INTRODUCTION}

Corrosion of reinforcement due to chloride attack is a common cause of deterioration for RC structures. Steel corrosion induces cracks and concrete spalling, which can lead to significant reduction of their service lives and safety concerns. Andrade, Alonso, and Molina (1993) and Otsuki, Miyazato, Diola, and Suzuki (2000) reported the propagating and widening times of corrosion cracking were longer than the corrosioninduced cracking time; and the steel cross-section loss, which was associated with the crack width, did not significantly affect the ultimate state but did affect the serviceability state. Consequently, deteriorated $\mathrm{RC}$ structures represent a considerable economic loss due to maintenance and repair work. Therefore, the reliable prediction method of the long-term performance of deteriorated existing RC structures is important for on-time maintenance and rehabilitation.

Recently, efforts have been made to estimate the long-term structural performance of deteriorated RC structures by using probabilistic concepts and methods (Marsh \& Frangopol, 2008; Mori \& Ellingwood, 1993). However, limited amounts of experimental data on the relationship between the spatial variability of steel weight loss and surface crack widths have been reported, creating difficulties in improving the degree of accuracy of the prediction models (Akiyama, Frangopol, \& Yoshia, 2010). Although it is possible to study this relationship via the destructive method by repeatedly breaking specimens to weigh the steel bar at various corrosion times, this method might be inefficient and error-prone due to difficulties in making the same experimental conditions repeatable and some other uncertainties (e.g., different cracking patterns and cracking widths of different specimens used).

Alternatively, the use of X-ray technique can be a better option since it enables a continuous investigation of corroded bars throughout the corrosion process. Presently, there have been a few studies using X-ray technique to investigate steel corrosion. Beck, Goebbels, Burkert, Isecke, and Babler (2010) used X-ray computer tomography to examine the surface of a very small steel cylinder $(9 \mathrm{~mm}$ in diameter and $10 \mathrm{~mm}$ long) at various stages of corrosion inside a mortar specimen. The reported difference between the mass loss, which was determined using the constructed 3-D X-ray tomography image and the actual mass loss after breaking the specimen, was 40-60\%. Akiyama and Frangopol (2012) suggested the X-ray apparatus was a suitable tool for a continuous investigation of a corroded rebar in a concrete cylinder $(100 \mathrm{~mm} \times 200 \mathrm{~mm})$ and prism $(100 \mathrm{~mm} \times 100 \mathrm{~mm} \times 400 \mathrm{~mm})$. The weight loss of the corroded steel bar was estimated by a digital image analysis of $\mathrm{X}$-ray photograms of a corroded steel bar from different viewing angles. The estimated steel weight loss using photograms was found to be different by only $10 \%$ from that of measured weight loss.

The main objective of this paper is to experimentally investigate the continuous growth of non-uniform spatial distribution of steel weight loss along a corroded steel rebar inside a RC beam via X-ray technique and digital image processing. The relationship between steel weight loss and its associated crack widths is discussed. Moreover, the validity of the estimation method is also presented. 


\section{TEST PROGRAMS}

\subsection{Test specimen and materials}

A RC beam ( $80 \mathrm{~mm} \times 140 \mathrm{~mm} \times 1460 \mathrm{~mm})$, reinforced with a tensile bar and stirrups, as shown in Figure 1, was used. All steel bars have the same steel grade SD345. The corrosion effect of the stirrups was excluded by wrapping them around with vynil tape to prevent contact with the tensile bar. The concrete compressive strength was $35 \mathrm{Mpa}$. The mixing proportion by weight was as follows: cement:sand:gravel:water-to-cement ratio $=1: 2.08: 2.65: 0.5$.

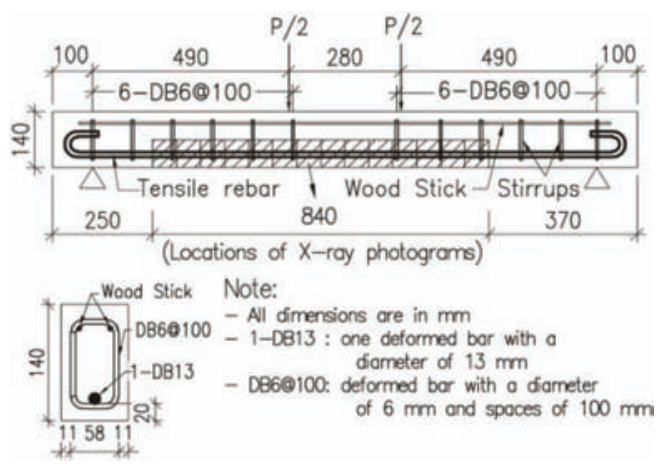

Figure 1. Details of specimen.

\subsection{Accelerated corrosion test}

After the 28-day curing of the specimen, the accelerated corrosion test of the tensile steel bar, as shown in Figure 2, was performed for a period of about 26 days. Within this period, the test was halt for several time lapses in order to collect the data of steel corrosion and cracking at various stages of corrosion. The current density used was $1000 \mu \mathrm{A} / \mathrm{cm}^{2}$.

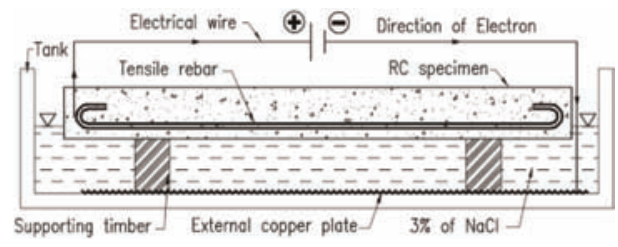

Figure 2. Accelerated corrosion test.

\subsection{Measurement of crack widths}

Before performing X-ray radiography, photographs of the longitudinal surface cracking were taken at the bottom of the specimen which is the only place that the surface crack occurred. The locations of the taken photographs were corresponded to those locations of captured X-ray photograms (see Figure 1). Seventeen times of $50-\mathrm{mm}$-long photographs were taken. Measurement of crack widths on the photographs was performed for every $5 \mathrm{~mm}$ by using an advanced image analysis program.

\subsection{X-ray photogram acquisition}

Once before the corrosion test and several times during the test, photograms of the non-corroded and corroded steel bars inside the specimen were taken from different viewing angles using the X-ray configuration in Figure 3. For bar length of $840 \mathrm{~mm}$, 60-mm-long images were captured 14 times continuously along the steel bar (see Figure 1). By rotating the specimen as shown in Figure 4, images of the steel bar from eight different viewing angles (i.e., $\theta_{1}=0^{\circ}, \theta_{2}=30^{\circ}, \theta_{3}=90^{\circ}, \theta_{4}=150^{\circ}, \theta_{5}=180^{\circ}$, $\theta_{6}=210^{\circ}, \theta_{7}=270^{\circ}$, and $\theta_{8}=330^{\circ}$ ) were obtained. The acquired $\mathrm{X}$-ray photograms are 8 -bit grey-scale images which consist of $1024 \times 768$ pixels.

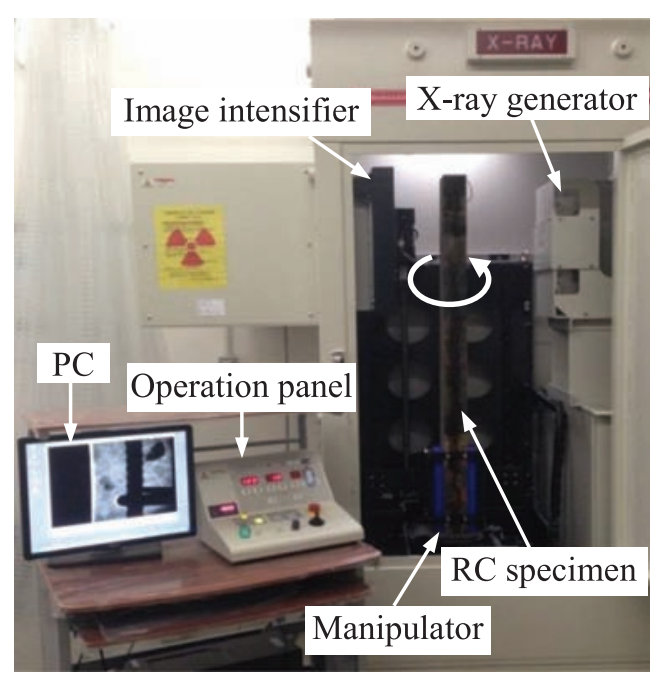

Figure 3. X-ray apparatus used to acquire photograms.

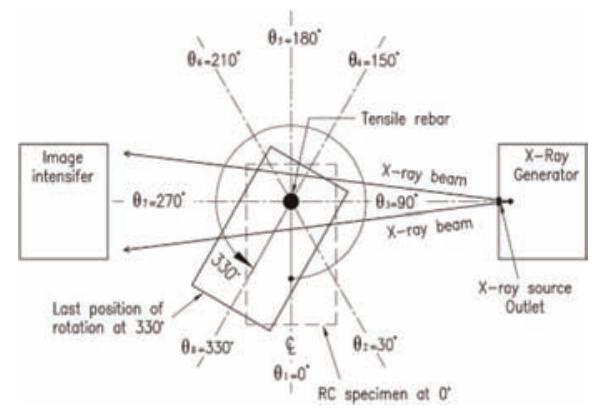

Figure 4. Viewing angles used to capture photograms.

\section{ESTIMATING PROCEDURE FOR STEEL WEIGHT LOSS}

\subsection{Image Enhancement}

Some original X-ray photograms of the non-corroded steel bar at eight different viewing angles are shown in Figure 5. Generally, the clearest views of images are obtained at $0^{\circ}$ and $180^{\circ}$, followed by those at $30^{\circ}, 150^{\circ}, 210^{\circ}$, and $330^{\circ}$, whereas the worst ones 
were obtained at $90^{\circ}$ and $270^{\circ}$. These results are due to the differences in the concrete thickness through which the X-ray beam penetrated as the specimen was rotated to a particular angle (see Figure 4). Therefore, the X-ray images were enhanced, as shown in Figure $6 \mathrm{~b}$, to obtain much sharper contrast among objects than the original image in Figure $6 a$. This enhancement facilitates the area segmentation between steel rebar and concrete in the analysis stage.

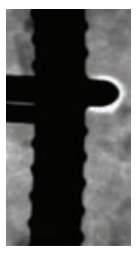

(a)

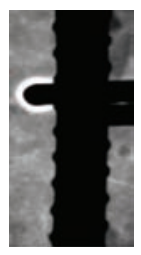

(e)

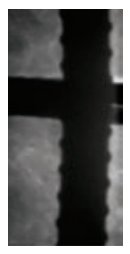

(b)

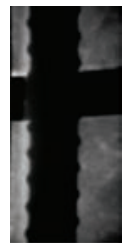

(f)

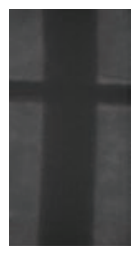

(c)

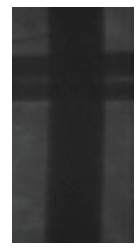

(g)

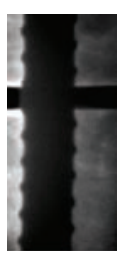

(d)

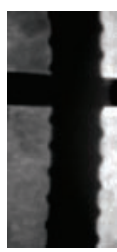

(h)
Figure 5. (a)-(h) X-ray photograms of the original steel bar taken from viewing angles $0^{\circ}, 30^{\circ}, 90^{\circ}, 150^{\circ}, 180^{\circ}, 210^{\circ}, 270^{\circ}$, and $330^{\circ}$, respectively.

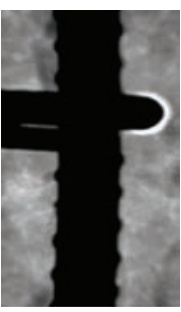

(a)

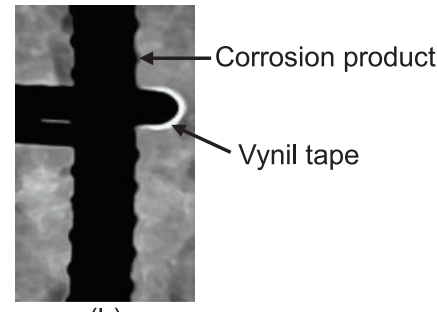

(b)
Figure 6. X-ray photograms of steel corrosion at $0^{\circ}$ (a) before enhancement and (b) after enhancement at MSW of $8.79 \%$.

\subsection{Estimation method of steel weight loss and its validity}

To estimate the weight loss of the corroded rebar, the longitudinal area of non-corroded bar and that of the corroded rebar at a given corrosion time need to be determined. At each angle and corresponding locations, the two types of areas are determined via digital image processing of X-ray photograms.

Basically, the greyness levels of the pixels in the X-ray images are numerically presented by 256 intensity values, ranging from 0 for completely black to 255 for completely white. Since the steel bar is the densest material compared to the concrete and corrosion product, it absorbs the $\mathrm{X}$-ray radiation most efficiently and thus produces darkest pixels with lowest intensity range in the images. By manipulating the numeric values or intensities of the pixels, it is possible to select and quantify the steel bar area alone by specifying a threshold of lowest intensity range. To facilitate the analysis, the image was sliced into $5-\mathrm{mm}$ images as shown in Figure 7. The histogram in Figures $8 \mathrm{a}$ and $8 \mathrm{~b}$ shows the cumulative number of pixels, which are classified according to the intensity values of the two images of the non-corroded and corroded bars in Figures $7 \mathrm{a}$ and $7 \mathrm{~b}$, respectively. In Figures $8 \mathrm{a}$ and $8 \mathrm{~b}$, the numbers of pixels 8732 and 8449 are obtained by counting pixels of the intensity thresholds of $0-57$ and $0-58$, which are the area of the non-corroded and corroded steel bars in Figures $7 \mathrm{a}$ and $7 \mathrm{~b}$.

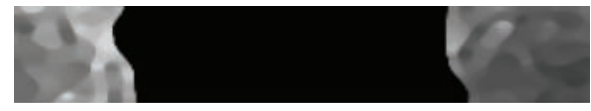

(a)

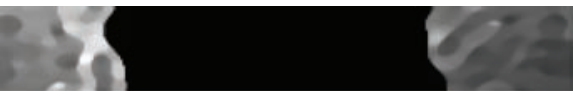

(b)

Figure 7. Five-millimeter-long $X$-ray images at $0^{\circ},(a)$ an original bar and (b) a corroded bar at $M S W=6.03 \%$.

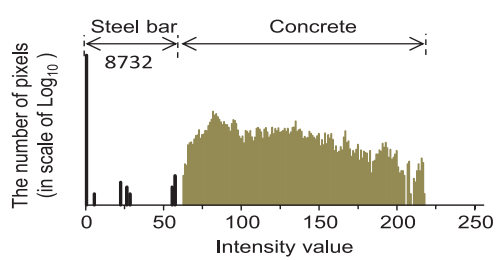

(a)

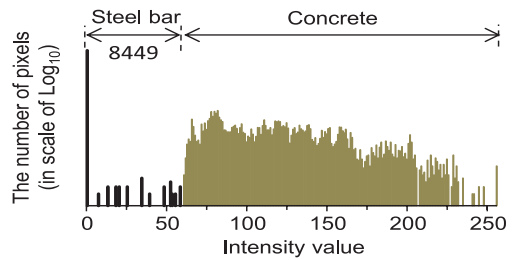

(b)

Figure 8. Histograms of pixels classified according to the intensity values for (a) an original bar and (b) a corroded bar $(M S W=6.03 \%)$.

The steel weight loss per length $L(\mathrm{~mm})$ can be estimated by averaging the steel weight loss per length $L$ from all viewing angles:

$$
S W=\frac{1}{k} \sum_{n=1}^{k} \frac{\left(W_{\theta n}-W^{\prime}{ }_{\theta n}\right)}{W_{\theta n}} \times 100
$$

where $S W$ is local steel weight loss per $L ; W^{\prime}$ and are weights per $L$ of the non-corroded and corroded bars, respectively; $\theta_{n}$ is viewing angles $(n=1, \ldots, k)$; and $k$ is the number of viewing angles. 
After the experimental tests, the corroded bar was removed from $\mathrm{RC}$ specimen and immersed into the water containing $10 \%$ diammonium hydrogen citrate solution for $24 \mathrm{~h}$ to clean the corrosion product. Next, the corroded rebar was weighted by a digital scale. The measured weight loss was found to be $16.63 \%$, about $3 \%$ greater than the estimated weight loss $19.65 \%$ by digital image processing.

\section{RESULTS AND DISCUSSIONS}

\subsection{Spatial distribution of steel weight loss and surface crack widths}

Figure 9 shows the growth of spatial variability of the steel weight loss SW and its associated surface crack width $C W$ along the specimen length at various stages of corrosion (i.e., from MSWs of 0.68 to $19.65 \%$ ). Note since the data of SW could not be obtained from the photograms at the locations of stirrups, there are some gaps of the line in the graph.

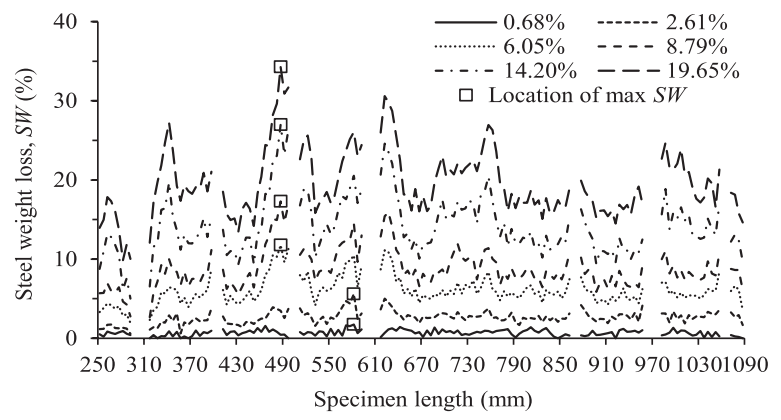

(a)

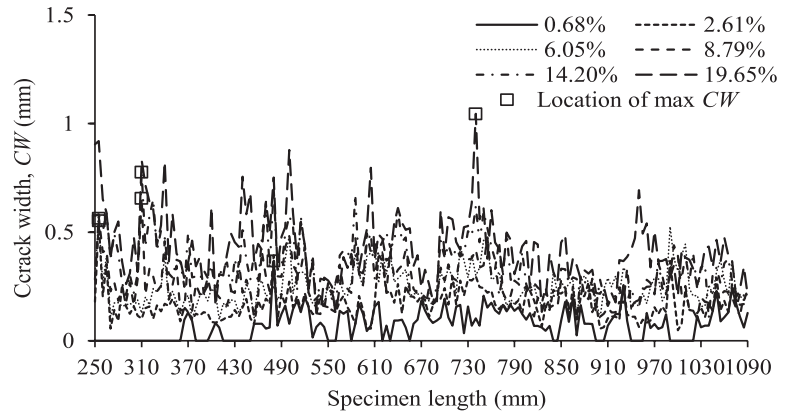

(b)

Figure 9. Spatial distribution of (a) steel weight loss along the corroded rebar and (b) surface crack widths along the bottom specimen.

Generally, the distribution of steel weight loss is, as expected, spatially non-uniform along the specimen length. The degree of the non-uniformity seems insignificant at the relatively low MSW of $0.68 \%$ but becomes increasingly volatile as MSW is over $2.61 \%$. At different MSWs, the global maxima of SW as indicated by rectangular symbols might shift to different locations, and these points and other local maxima often occur close to the locations of stirrups.
This may be because the concrete covers at the locations of the stirrups are thinner than those at other locations, which expose the longitudinal bar close to the stirrups to chloride attack more quickly.

\subsection{Relationship between steel weight loss and surface crack widths}

Figure 10 shows the relationship between the steel weight loss and the surface crack widths. Although the scattered points become more dispersed as MSW becomes larger, a good trend is shown where CW tends to increase with the increase of $S W$.

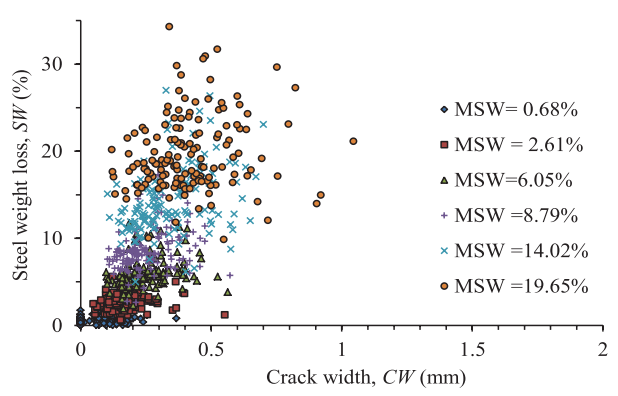

Figure 10. Relationship between the steel weight loss and surface crack widths.

\section{CONCLUSION}

In this study, the novel procedure of X-ray technique application in continuous monitoring spatial growth of a corroded steel bar inside the RC means has been presented with the estimation method of steel weight loss via digital image processing and its validity. The following conclusions can be drawn:

(1) The estimation method of steel weight loss using the X-ray technique and digital image processing has been established with a proven good accuracy.

(2) The distribution of steel weight loss along a steel bar is spatially non-uniform, and its non-uniform degree significantly increases as the mean steel weight loss increases.

(3) Maxima of steel weight loss occur at locations close to the stirrups, and their locations might shift as the mean steel weight loss increases.

A possibly good relationship between steel weight loss and crack width can be established. However, further experimental studies with more parameters are needed to determine this relationship.

\section{REFERENCES}

Akiyama, M., \& Frangopol, D. M. (2012). Estimation of steel weight loss due to corrosion in RC members based on digital image processing 
of X-ray photogram. Proceedings of the Third International Symposium on Life-Cycle Civil Engineering, IALCCE2012, Vienna, Austria, 1885-1891.

Akiyama, M., Frangopol, D. M., \& Yoshia, I. (2010). Time-dependent reliability analysis of existing RC structures in marine environment using hazard associated with airborne chlorides. Engineering Structures, 32(11), 3768-3779.

Andrade, C., Alonso, C., \& Molina, F. J. (1993). Cover cracking as a function of rebar corrosion: Part 2 Numerical model. Materials and Structures, 26(9), 532-548.

Beck, M., Goebbels, J., Burkert, A., Isecke, B., \& Babler, R. (2010). Monitoring of corrosion processes in chloride contaminated mortar by electrochemical measurement and X-ray tomography. Materials and Corrosion, 61(6), 475-479.

Marsh, P. S., \& Frangopol, D. M. (2008).

Reinforced concrete bridge deck reliability model incorporating temporal and spatial variations of probabilistic corrosion rate sensor data. Reliability Engineering \& System Safety, 93(3), 394-409.

Mori, Y., \& Ellingwood, B. R. (1993). Reliabilitybased service life assessment of aging concrete structures. Journal of Structural Engineering, 119(5), 1600-1621.

Otsuki, N., Miyazato, S.-I., Diola, N., \& Suzuki, H., (2000). Influences of bending crack and watercement ratio on chloride-induced corrosion of main reinforcing bars and stirrups. ACI Material Journal, 97(4), 454-464. 